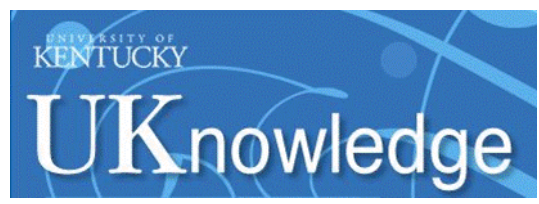

University of Kentucky

UKnowledge

Theses and Dissertations--Public Health (M.P.H.

\& Dr.P.H.)

College of Public Health

2014

\title{
Patterns of Pneumoconiosis Mortality in Kentucky: Analysis of Death Certificate Data
}

Jake Beggs

University of Kentucky

Follow this and additional works at: https://uknowledge.uky.edu/cph_etds

Part of the Public Health Commons

Right click to open a feedback form in a new tab to let us know how this document benefits you.

\section{Recommended Citation}

Beggs, Jake, "Patterns of Pneumoconiosis Mortality in Kentucky: Analysis of Death Certificate Data" (2014). Theses and Dissertations--Public Health (M.P.H. \& Dr.P.H.). 29.

https://uknowledge.uky.edu/cph_etds/29

This Dissertation/Thesis is brought to you for free and open access by the College of Public Health at UKnowledge. It has been accepted for inclusion in Theses and Dissertations--Public Health (M.P.H. \& Dr.P.H.) by an authorized administrator of UKnowledge. For more information, please contact UKnowledge@lsv.uky.edu. 


\section{STUDENT AGREEMENT:}

I represent that my capstone and abstract are my original work. Proper attribution has been given to all outside sources. I understand that I am solely responsible for obtaining any needed copyright permissions. I have obtained needed written permission statement(s) from the owner(s) of each third-party copyrighted matter to be included in my work, allowing electronic distribution (if such use is not permitted by the fair use doctrine) which will be submitted to UKnowledge as Additional File.

I hereby grant to The University of Kentucky and its agents the irrevocable, non-exclusive, and royalty-free license to archive and make accessible my work in whole or in part in all forms of media, now or hereafter known. I agree that the document mentioned above may be made available immediately for worldwide access unless an embargo applies.

I retain all other ownership rights to the copyright of my work. I also retain the right to use in future works (such as articles or books) all or part of my work. I understand that I am free to register the copyright to my work.

\section{REVIEW, APPROVAL AND ACCEPTANCE}

The document mentioned above has been reviewed and accepted by the student's advisor, on behalf of the advisory committee, and by the Director of Graduate Studies (DGS), on behalf of the program; we verify that this is the final, approved version of the student's capstone including all changes required by the advisory committee. The undersigned agree to abide by the statements above.

Jake Beggs, Student

Terry Bunn, PhD, Committee Chair

Linda Alexander, EdD, Director of Graduate Studies 


\title{
PATTERNS OF PNEUMOCONIOSIS MORTALITY IN KENTUCKY: ANALYSIS OF DEATH CERTIFICATE DATA
}

\section{CAPSTONE PROJECT PAPER}

This paper is submitted as a portion of the requirements to complete a degree of Master of Public Health with a concentration in Environmental Health from the University of Kentucky

\section{By}

\author{
Jake Beggs, BS \\ Paducah, KY
}

Lexington, KY

November, 2014

Terry Bunn, Ph.D., Committee Chair

Svetla Slavova, Ph.D., Committee Member

David Mannino, M.D., Committee Member 


\section{ABSTRACT}

Background: Despite ongoing surveillance efforts, mortality rates associated with total pneumoconiosis, and particularly coal worker's pneumoconiosis, have remained elevated.

Methods: Kentucky death certificate data from 2003-2011 was statistically compared to other coal mining states and descriptively analyzed from 2011-2013 to determine the mortality burden and public health implications of pneumoconiosis and coal worker pneumoconiosis (CWP) on Kentucky residents from 2003-2013.

Results: Kentucky's total pneumoconiosis and coal workers' pneumoconiosis mortality rates decreased from 2003-2009, then increased in following years, showing a significant quadratic trend from 2003-2013 ( $p<.05)$ compared to West Virginia, Pennsylvania, and the overall United States rates that had significant negative linear trends from 2003-2011( $p<.05)$. Deaths from pneumoconiosis primarily occurred in white males from CWP in the Appalachian region. Individuals diagnosed with pneumoconiosis died from respiratory illness $50 \%$ of the time, heartrelated problems (23\%) and cancer (12\%). Autopsies were only performed on $12 \%$ of decedents over the three year study period and the primary locations of death were in hospital (47\%) and at home (36\%).

Conclusions: Increased coal mining industry worker environmental exposure protection should be enhanced in Kentucky. Additionally, healthcare efforts should focus on increasing patient education to ensure early detection and treatment for individuals suffering from pneumoconiosis as well as for comorbid conditions such as Chronic Obstructive Pulmonary Disease. To further target healthcare and treatment of pneumoconiosis patients, increased autopsies of individuals with pneumoconiosis should be performed to identify involvement of other conditions such as silicosis and optimize pneumoconiosis fatality surveillance. 


\section{Introduction}

Over the past three decades, overall US mortality rates of the occupational lung disease, pneumoconiosis, have decreased (Centers for Disease Control and Prevention , 2014). Pneumoconiosis refers to a group of respiratory illnesses that are related to inhalation of mineral dusts and fibers. The primary types of pneumoconiosis are coal workers' pneumoconiosis resulting from inhalation of coal dust, silicosis from inhalation of crystalline silica, and asbestosis from inhalation of asbestos fibers. Detection and severity of these diseases is based on radiographic findings and is classified based on the International Labor Organization (ILO) guidelines (2000). Clinically, pneumoconiosis may be hard to detect due to the long latency period between exposure and onset of illness. There are currently no options to cure individuals with pneumoconiosis and in severe cases that progress to chronic respiratory failure, lung transplantation may be the only treatment option (Hayes Jr., et al., 2012).

Geographically, elevated rates of pneumoconiosis have been observed in the regions of eastern Kentucky, western Virginia, southern West Virginia, and eastern Pennsylvania, relative to U.S. rates, and rates seen in other coal mining areas. Due to the coal mining workforce in Kentucky, employing over 11,000 individuals, primarily in the Eastern and Western Kentucky coal fields, most pneumoconiosis in Kentucky is coal worker pneumoconiosis (CWP) or "black lung disease" (Wang, et al., 2013). CWP in Kentucky has been linked to mine size, with employees in small mines having a 2.1 times higher prevalence of CWP and $37 \%$ higher prevalence of abnormal spirometry when compared to those in large mines. Additionally, progressive massive fibrosis (PMF), a severe fatal form of CWP, is seen in $2.4 \%$ of small mine miners compared to $1.1 \%$ of large mine miners (Blackley, et al., 2014). 
The prevalence of pneumoconiosis in Appalachian regions has been increasing in recent years, despite stringent regulations following the 1969 Federal Coal Mine Safety and Health Act. PMF was nearly eradicated in coal mines only 15 years ago with a prevalence of only $0.08 \%$ for those who participated in the Coal Worker Health Surveillance Program (CWHSP). However, in Appalachian miners, the prevalence of PMF reached 3.23\% in 2012 (Blackley, et al., 2014), reflecting the need for additional efforts in order to adequately protect Kentucky coal miners. There has not only been an increase in prevalence, but also in the severity of pneumoconiosis for younger miners with less cumulative exposure. In a study done on underground coal miners from 2005-2009, when compared to 12 other states, miners in Kentucky, Virginia, and West Virginia, had a greater risk of advanced CWP $(R R=8.1)$, progressive massive fibrosis $(R R=$ 10.5), and r-type opacities $(R R=7.7)$, in younger miners with less mining tenure (Laney, et al., 2012).

In addition to the relationship between coal mining and pneumoconiosis, exposures in mines may also be related to a number of other diseases, including cancers of the stomach and lung, and other respiratory diseases like chronic bronchitis, emphysema, chronic airway obstruction, and COPD (Petsonk, et al., 2013). A 23 year follow-up study of 8,899 working coal miners showed elevated mortality from nonmalignant respiratory diseases, even among miners who did not smoke. However, there were not excess mortalities associated with lung and stomach cancers. While lung cancer rates were not elevated, there may have been other factors making lung cancer harder to detect in this population (Attfield \& Kuempel, 2008). This is in contrast to a German study of coal miners which showed an increase in stomach cancer related to coal worker pneumoconiosis (Morfeld, et al., 1997). Pneumoconiosis may also exacerbate symptoms in those who have COPD. A study published in La Clinica Terapeutic found that 
patients admitted to the hospital with acute exacerbation of COPD (AECOPD) who also had complicated CWP had significantly longer hospitalizations (Ornek, et al., 2013). Because of the relationship between coal mining and a number of other respiratory and non-respiratory ailments, CWP may play a role in the onset, severity, progression, and subsequent health outcomes of other diseases from exposure in mines.

Due to the severity of the disease and the health burden on states like Kentucky, the Coal Workers' Health Surveillance Program, a surveillance program under the National Institute for Occupational Safety and Health (NIOSH), has recently expanded (2014) to cover surface miners, in addition to underground coal miners. This expansion came as a result of the Mine Safety and Health Act's (MSHA) final ruling on exposure to coal dust, which also resulted in lowering coal dust standards (2014). While lowering the coal dust standards may be a step in the right direction, it still may not effectively combat the issue of crystalline silica exposure in mines. Silicosis, caused by crystalline silica exposure, may be largely underreported or miscategorized on death certificates. In a study in New Jersey, $8.5 \%$ of individuals who worked in industries and died of COPD, cor pulmonale, or tuberculosis, also had signs of silicosis (Goodwin et al., 2003). Rosenman et al. (2003) also determined that employee reporting systems were inadequate for accurately reporting silicosis deaths.

The aim of this study was to perform a descriptive analysis of pneumoconiosis mortality patterns in Kentucky using death certificate data from 2011-2013, in order to better understand the total health burden and public health implications of pneumoconiosis. The study objectives were to: (1) characterize pneumoconiosis deaths by demographics; (2) calculate mortality rates from or with total pneumoconiosis and CWP in Kentucky compared to overall U.S. and other coal mining state rates; (3) identify comorbid conditions when pneumoconiosis was listed as the 
underlying or contributing disease of death, and (4) identifying the death certifier, autopsy performance and location of death. Secondary objectives of this study were to compare pneumoconiosis mortality patterns between the Kentucky Appalachian and non-Appalachian coal mining regions.

\section{Methods}

A retrospective analysis of deaths from or with pneumoconiosis was performed over a three year period, from 2011-2013, using Kentucky Office of Vital Statistics death certificate data for Kentucky residents, 15 years of age or older. Electronic death certificate data was provided by the Kentucky Cabinet for Health and Family Services, Office of Vital Statistics. The 2011-2013 KY death certificate data are provisional and subject to change. Previous Kentucky, West Virginia, Pennsylvania, and U.S. pneumoconiosis mortality data, 2003-2011, were obtained from the U.S. National Center for Health Statistics’ National Vital Statistics System, Mortality Multiple Cause-of-Death Data. This study was performed at the Kentucky Injury Prevention and Research Center (KIPRC), a joint entity between the University of Kentucky, College of Public Health and the Kentucky Department for Public Health. This study was part of the Kentucky Occupational Safety and Health Surveillance program, and was approved by the University of Kentucky Institutional Review Board.

The study subjects were individuals who had died in Kentucky with some form of pneumoconiosis during the three year study period as indicated on their death certificates. Causes of death listed on the death certificates are coded according to the guidelines of the Tenth Revision of the International Classification of Disease (ICD-10) for standardized classification and grouping (World Health Organization, 2010). All death certificates in the U.S. are coded with a single underlying cause of death (UCOD) using ICD-10 codes and can have up to 20 
additional codes to specify contributing causes. For the purpose of this study, the following ICD-10 codes were utilized for case selection as the underlying or contributing cause of death: J60-J66 (total pneumoconiosis), J60 (coal workers' pneumoconiosis), J61 (asbestosis), J62 (silicosis), J63-J66 (other and unspecified pneumoconiosis). Death certificate coding data were converted into text format and uploaded as spreadsheets for descriptive analysis.

Relevant information from the death certificates that was used to perform this study included basic demographic data such as sex, date of birth, race, birthplace, location of death, and industry that the individual worked in. Additionally, death certificate information included whether a physician or a coroner certified the death as well as whether a subsequent autopsy was performed. Descriptive analysis for a number of variables was performed in Microsoft Excel. Frequencies tabulated for demographic data included gender, ethnicity, industry, and location of death for Appalachian vs. non-Appalachian regions. Appalachian regions were determined by county. Kentucky Appalachian counties included: Adair, Bath, Bell, Boyd, Breathitt, Carter, Casey, Clark, Clay, Clinton, Cumberland, Edmonson, Elliott, Estill, Fleming, Floyd, Garrard, Green, Greenup, Harlan, Hart, Jackson, Johnson, Knott, Knox, Laurel, Lawrence, Lee, Leslie, Letcher, Lewis, Lincoln, McCreary, Madison, Magoffin, Martin, Menifee, Metcalfe, Monroe, Montgomery, Morgan, Nicholas, Owsley, Perry, Pike, Powell, Pulaski, Robertson, Rockcastle, Rowan, Russell, Wayne, Whitley, and Wolfe (Appalachian Regional Commission, 2008).

ICD-10 coding of pneumoconiosis as an underlying or contributing cause of death was used to determine the overall number of pneumoconiosis deaths. Frequencies were counted for each year (2011-2013) and for each specific type of pneumoconiosis as defined by ICD-10 codes J60-J66. The World Health Organization defines the underlying cause of death as the disease responsible for initiating the events preceding death or the circumstances directly involved in the 
outcome of the fatal injury (2010). Frequencies less than 5 were suppressed due to the state data management policy.

The National Center of Health Statistics’ Multiple Cause of Death mortality files (2014) were used to calculate deaths and mortality rates for 15 years of age and older residents of Kentucky, West Virginia, Pennsylvania, and the U.S., 2003-2011. Trends in Kentucky rates from 2003-2011 were compared to West Virginia and Pennsylvania, two of the other top coal producing states in this region of the country, as well as to the overall U.S. rates. Mortality rates were calculated using population statistics from the U.S. Census Bureau. These rates were calculated using direct age-adjustment per one million residents (Council of State and Territorial Epidemiologists, 2014). A trend analysis utilizing liner and polynomial regressions was performed in Microsoft Excel to determine the significance of the changes in the pneumoconiosis rates over the specified time period for each state and for the U.S.

North American Industry Classification System (NAICS) codes were used to identify industries. Mining refers to all deaths related to Metal Mining, Coal Mining, Oil and Gas Extraction, and Mining and Quarrying of Nonmetallic Minerals, Except Fuels. Frequencies of deaths for "All Other industries" included: Agriculture, Forestry, \& Fishing, Construction, Manufacturing, Transportation, Communication, Electric, Gas \& Sanitary Services, Wholesale Trade, Retail Trade, Finance, Insurance \& Real Estate, Services, and Public Administration.

\section{Results}

\section{A. Historical trends in mortality rates from or due to pneumoconiosis, 2003-2011}

Table 1 shows the number and the age-adjusted rates for total pneumoconiosis deaths for residents of Kentucky, West Virginia, Pennsylvania, and the U.S., who were 15 years of age or older at the time of the death, 2003-2011. Total pneumoconiosis mortality rates showed a 
significant linear decrease in West Virginia ( $\mathrm{p}$-value $<0.0001)$, Pennsylvania (p-value $<0.0001)$ and the U.S. (p-value<0.0001), 2003-2011 (Figure 1). The total pneumoconiosis fatality rate in West Virginia decreased from 132 deaths/million residents in 2003 to 80.6/million in 2011, a 39\% decrease, but remained more than 10 times above the 2011 U.S. total pneumoconiosis mortality rate of 7.2/1 mill. The average annual decrease in West Virginia was 6 deaths per 1 mill residents. The Pennsylvania total pneumoconiosis age-adjusted rate showed a significant decrease of about 3 deaths per million residents annually. Pennsylvania and Kentucky had comparable total pneumoconiosis mortality rates in 2003: 36.3/1 mill in Kentucky and 37.2/1mill in Pennsylvania. By 2011, the total pneumoconiosis mortality rate in Kentucky decreased to 31.9/1 mill. A quadratic regression ( $\mathrm{p}$-value $=0.015, \mathrm{R}^{2}=0.753$ ) was a better fit to the Kentucky mortality trend 2003-2011 than a linear regression ( $\mathrm{p}$-value $=0.022, \mathrm{R}^{2}=0.553$ ). Figure 1 shows that after an initial decrease from 2003 to 2009 the Kentucky total pneumoconiosis rate started increasing in the following two years. Kentucky total pneumoconiosis fatality rates for 2012 and 2013, calculated from state death certificate data, were lower than the 2011 rate but still above the lowest 2009 rate. The re-fitted polynomial regression on 2003-2013 Kentucky total pneumoconiosis mortality rates showed a quadratic trend ( $\mathrm{p}$-value $=0.005, \mathrm{R}^{2}=0.734$ ).

Similar results were observed for the CWP mortality rates. From 2003-2011, there was a significant linear decrease for West Virginia ( $\mathrm{p}=0.0005)$, Pennsylvania $(\mathrm{p}<0.0001)$, and the U.S. ( $\mathrm{p}<0.0001$ ) (Figure 1). The CWP rate in WV decreased from 84.4/million in 2003 to 41/million in 2011, a nearly 50\% decrease over the 9-year period, but was still much higher than KY, PA, and overall U.S. rates. Again, rates of CWP were similar in 2003 in Kentucky and Pennsylvania, with 26.9/million and 23.4/million, respectively, but Pennsylvania rates decreased 74\% while Kentucky rates decreased only 17\% (Table 1). West Virginia showed a significant decrease in 
the number of resident CWP deaths annually with an average of 5 fewer per million, while Pennsylvania CWP deaths also decreased significantly, with 2 fewer deaths per million residents annually. A quadratic trend (p-value=0.014, rsquare=0.654) was found for Kentucky CWP rates from 2003-2011, where rates decreased from 2003 to their lowest in 2009 (19.3/1 mill). After 2009, CWP rates began to increase; a polynomial regression for 2003-2013 showed a quadratic trend $(\mathrm{p}$-value $=0.011$, rsquare $=0.778)$ for Kentucky $($ Figure 1$)$.

\section{B. Kentucky pneumoconiosis deaths, 2011-2013}

\section{Demographics and Number of Deaths}

Nearly all of the deaths from or with pneumoconiosis in Kentucky from 2011-2013 were in males $(98 \%)$ that were white $(99 \%)$. The average age of death from pneumoconiosis (75) slightly decreased in Kentucky over the three year period, with ages of death ranging from 34100. Mining was most frequently listed as the industry associated with death (78\%) compared to all other industries listed on the death certificates (22\%). There were a total of 330 pneumoconiosis deaths identified with pneumoconiosis as the underlying or contributing cause of death (Table 2). Of these deaths, 125 listed pneumoconiosis as the underlying disease associated with the death. Of the 330 pneumoconiosis deaths, there were 238 deaths from CWP, 33 from asbestosis, 7 from silicosis, and 52 identified as other pneumoconiosis as an underlying or contributing disease. The majority of deaths were from CWP.

\section{Appalachian vs. Non-Appalachian}

The Appalachian areas of Kentucky experienced a greater number of deaths and higher crude mortality rates due to pneumoconiosis than non-Appalachian counties. Of the 330 total deaths from pneumoconiosis within Kentucky, 260 were residents of Appalachian counties compared to 70 residents of non-Appalachian counties. Additionally, deaths from CWP were 
greater in Appalachian regions, accounting for 199 of the 238 deaths. Crude mortality rates from pneumoconiosis and CWP were 73.4 and 56.2, respectively, for Appalachia, compared to 7.3 and 4.1 for non-Appalachia. The number of deaths from asbestosis over the three year period was similar between Appalachia and non-Appalachia, with 18 and 15 deaths, respectively; there were less than five deaths from silicosis in the non-Appalachian region and 6 silicosis deaths in Appalachia. Unspecified types of pneumoconiosis accounted for 52 deaths from 2011-2013. The average age of death from or with pneumoconiosis was slightly lower in Appalachian regions than in non-Appalachian regions; however, the average age of deaths was virtually the same in 2013 for both areas of Kentucky.

\section{Causes of Death due to Pneumoconiosis}

Of the 125 deaths where pneumoconiosis was considered the underlying cause of death, the immediate cause of death was primarily due to respiratory diseases; specifically, respiratory failure (46), COPD (42), pneumoconiosis (22), CWP (12), and pneumonia (26) (Figure 3). There were 23 deaths where the immediate cause of death involved the heart. Of the 330 total cases where pneumoconiosis was an underlying or contributing cause of death, the immediate cause of death was largely due to respiratory conditions, with 46 deaths from respiratory failure and 42 from COPD. However, there were also a large proportion of heart-related deaths, with 37 from cardiac arrest, as well as various forms of cancer, specifically lung cancer, listed as the immediate cause of death.

\section{Location of Death, Autopsies Performed and Certifier of Death}

The percentage of pneumoconiosis deaths in hospital decreased every year from 20112013. The second most common location of death was the patient's residence (36\%), which slightly increased from 2011 to 2013 (Table 3). The percentage of pneumoconiosis patients who 
died in a nursing home/ long-term care facility increased from $4 \%$ in 2011 to $8 \%$ in 2013 . A physician certified the pneumoconiosis death $84 \%$ of the time. This proportion stayed relatively the same over the three year period. In a majority of the cases, those who certified the death did not perform an autopsy over the three year period. Autopsies to confirm the suspected cause or causes of death were only performed on $12 \%$ of the decedents in Kentucky over the three year period (Figure 4).

\section{Discussion}

Pneumoconiosis white male demographic results are similar to previous findings by Attfield et al. (2008) and Wang (2013) pertaining to race and gender most affected by pneumoconiosis. While the average age of pneumoconiosis death in Appalachian county residents was lower than non-Appalachian county residents from 2011-2013, the age of death for non-Appalachian pneumoconiosis decedents decreased every year over the three year period, reaching the average age of death in the Appalachian group in 2013. While more research is needed to determine if the average age of death is truly decreasing for pneumoconiosis decedents in Kentucky, this may support findings suggesting that individuals are getting severe forms of CWP at younger ages, and thus are dying younger with less mining tenure (Laney et al., 2012). This data result is also important because it supports the notion that even young miners with less mining tenure can be greatly affected by the disease.

Of all deaths associated with pneumoconiosis, CWP was the most frequent cause among decedents in Kentucky. However, it is important to note that, while the number of silicosis deaths from 2011-2013 only averaged 2.33 in Kentucky, a number of deaths from crystalline silica exposure may have been miscategorized as coal workers' pneumoconiosis or other respiratory diseases. Silicosis deaths, which are on the decline, have largely been misdiagnosed 
over the years (Goodwin, et al., 2003). Therefore, silicosis deaths may be underestimated for the state.

West Virginia and Pennsylvania, who have also had historically higher rates of pneumoconiosis and CWP, showed a significant linear decrease $(\mathrm{p}<.05)$ in mortality rates from 2003-2011. In contrast, Kentucky rates only slightly decreased from 2003-2010 and then began to increase for total pneumoconiosis and CWP from 2010-2013. This is despite increases in disease surveillance and safety regulations, as well as a declining coal mining workforce in Kentucky, with a reported 15.5\% decrease in Kentucky coal mining jobs in 2013 alone (Patrick, et al., 2014). Although the rates for 2012 and 2013 in West Virginia and Pennsylvania are unavailable for comparison, the overall trend in pneumoconiosis and CWP mortality for Kentucky has not reduced nearly to the extent that it has in these other two states. While the coal dust standard was recently lowered from 2.0 milligrams per cubic meter to 1.5 , more research is needed to determine if this will be enough to adequately reduce the prevalence and mortality from CWP because of potential exposure to crystalline silica.

Identifying the immediate medical cause of death with pneumoconiosis as an underlying or contributing disease is important for a number of reasons. Pneumoconiosis may increase the risk or exacerbate other respiratory diseases, heart diseases, and certain forms of cancer (Morfeld et al., 1997; Petsonk et al., 2013). Respiratory failure was the most frequent cause of death with pneumoconiosis as an underlying disease or contributing disease. A focus on prevention of respiratory failure, like noninvasive ventilation in patients with pneumoconiosis, may be an important factor in preventing respiratory health complications or death (Nava, et al., 2005). We also found that individuals who were diagnosed with pneumoconiosis frequently died of COPD. Although the association between COPD and pneumoconiosis is unclear (Meijers et al., 
1997), there is a known association between exposure to coal dust and COPD (Santo Tomas, 2011). Prevention of respiratory failure may be especially important for individuals who died at home $(36 \%)$.

When pneumoconiosis was a contributing disease, individuals died of heart-related causes $23 \%$ of the time. While we were unable to determine a clear association between pneumoconiosis and death from heart disease, a study by Landen et al. (2011) found an association between mortality from ischemic heart disease in individuals with CWP. Our study results may signify the need for close heart function monitoring in patients with pneumoconiosis. Cancer (all forms) was the immediate cause of death in $12 \%$ of the cases, with lung cancer being the most common type, when pneumoconiosis was a contributing disease. A positive causal relationship was found between diffuse interstitial fibrosis (DIT), which is caused by pneumoconiosis, and lung cancer (Katabami, et al., 2000). Healthcare providers who have observed significant DIT in patients with pneumoconiosis should routinely monitor these patients for early detection of lung cancer. In addition, lung cancer concerns for miners should not be limited only to miners who regularly smoke. Coal dust and crystalline silica exposure in miners have both been associated with an increased risk of mortality from lung cancer, even in miners who weren't smokers (Graber, et al., 2014).

Autopsies were performed on very few individuals who died from or with pneumoconiosis between 2011 and 2013. Autopsies can confirm or refute previous diagnoses, or lead to new diagnoses or previously unknown causes of death. For a disease like silicosis that has historically been misclassified (Goodwin, et al., 2003), an autopsy may important in preventing misdiagnosis and providing a more accurate means of disease surveillance. While we are unable to determine if pneumoconiosis deaths in Kentucky may have been misclassified or 
underreported, performing autopsies on individuals with a high risk of exposure to crystalline silica may help determine if silicosis rates are higher than reported.

\section{Limitations}

As is the case with any study involving death certificates, there are a number of limitations. First, clinicians may not list all of the individual's ailments on the death certificate. If pneumoconiosis was a contributing disease but the individual died of causes that the clinician believed were not associated with this particular disease, this may not be included, which could cause deaths from or with pneumoconiosis to be underreported. Vital statistics data from 2012 and 2013 is preliminary and may be subject to change. Because of this, the number of deaths and fatality rates may be underestimated due to missing death certificate data from Kentucky residents who died out of state.

Death certificate data depends on correct diagnosis of a particular ailment. Because pneumoconiosis has such a long latency period between exposure and onset of illness, death could be attributed to a number of other more common respiratory conditions, potentially causing underreporting of pneumoconiosis. This could especially be the case for an individual who worked in a coal mine early on in their adult life and then retired in a different industry. Misclassification of ICD-10 diagnosis codes may also be a limiting factor.

\section{Conclusions}

Despite the overall negative trend for pneumoconiosis in the U.S., Kentucky continues to be greatly affected by deaths from this disease, especially in Appalachian coal mining regions. The recent rise in mortality rates for pneumoconiosis and CWP and the lack of a decreasing linear trend, as seen in other coal mining states, indicate a need for continued disease 
surveillance efforts, in addition to improved workplace safety programs to prevent exposure to inorganic dusts known to cause pneumoconiosis. Although the respirable coal dust standards were recently lowered by MSHA, it is still unknown if this change will be an effective approach to a re-emerging problem. While lowering the coal dust standards is a step in the right direction, it will also require complete compliance of the coal industry, as well as ensuring active participation by employees in federal disease surveillance programs to detect pneumoconiosis symptoms early and avoid fatal disease progression. Kentucky should ensure that healthcare providers are properly educated on pneumoconiosis and related diseases in order to accurately diagnose and treat symptoms, especially for those with co-morbid conditions. Mortality numbers and rates provide a snapshot of pneumoconiosis in Kentucky but other state-based data sources that assess morbidity (Emergency department visits, inpatient hospitalizations will be useful for pneumoconiosis surveillance, along with federal surveillance programs like the CWHSP. More research needs to be done to better understand if the burden of pneumoconiosis is increasing in Kentucky. 


\section{References}

1. Appalachian Regional Commission (ARC), 2008. Map of Appalachian Counties. [Online] Available at: http://www.arc.gov/images/appregion/AppalachianRegionCountiesMap.pdf [Accessed 14 October 2014].

2. Attfield M, Kuempel E. 2008. Mortality among U.S. underground coal miners: a 23-year follow-up. Am J Ind Med 51(4):231-45.

3. Blackley D, Halldin C, Laney A., 2014. Resurgence of a debillitating and entirely preventable respiratory disease among coal miners. Am J Respir Crit Care Med 190(6):7089.

4. Blackley D, Halldin C, Wang M, Laney A. 2014. Smalll mine size is associated with lung function abnormality and pneumoconiosis among underground coal miners in Kentucky, Virgnina, and West Virginia. Occup Environ Med 71(10):690-4.

5. Centers for Disease Control and Prevention (CDC), 2014. All pneumoconioses: number of deaths, crude and age-adjusted death rates, U.S. residents age 15 and over, 1968-2010., Work-Related Lung Disease Surveillance System (eWoRLD).

6. Centers for Disease Control and Prevention (CDC), Nationa Center for Health Statistics (NCFHS), 2014. Multiple Cause of Death 1999-2011 on CDC WONDER Online Database. [Online] Available at: http://wonder.cdc.gov/mcd-icd10.html [Accessed October 2014].

7. Council of State and Territorial Epidemiologists (CSTE), 2014. Occupational health indicators: a guide for tracking occupational health conditions and their determinants 51-52.

8. Goodwin S, Stanbury M, Wang M, Silbergeld E, Parker J. 2003. Previously undetected silicosis in New Jersey decedents. Am J Ind Med 44:304-311.

9. Graber J, Stayner M, Cohen R, Conroy L, Attfield M. 2014. Respiratory disease mortality among US coal miners; results after 37 years of follow-up. Occup Environ Med 71(1):30-9.

10. Hayes Jr. D, Diaz-Guzman E, Davenport D, Zwischenberger J, Khorsravi M, Absher K, Hoopes C. 2012. Lung transplantation in patients with coal worker's pneumoconiosis. Clin Transplant 26(4):629-34.

11. International Labour Organization, 2000. Guidelines for the Use of the ILO International Classification of Radiographs of Pneumoconioses. Occupational Safety and Health Series 22:1-51.

12. Katabami M, Dosaka-Akita H, Honma K, Saitoh Y, Kimura K, Uchida Y, Mikami H, Ohsaki Y, Kawakami Y, Kikuchi K. 2000. Pneumoconiosis-related lung cancers: preferential 
occurence from diffuse interstitial fibrosis-type pneumoconiosis. Am J Repir Crit Care Med 162(1):295-300.

13. Landen D, Wassell J. 2011. Coal dust exposure and mortality from ischemic heart disease among a cohort of US coal miners. Am J Ind Med 54(10):727-733.

14. Laney A, Petsonk E, Hale J, Wolfe A, Attfield M. 2012. Potential determinants of coal workers' pneumoconiosis, advanced pneumoconiosis, and progressive massive fibrosis among underground coal miners in the United States, 2005-2009. Am J Public Health 102:279-83.

15. Meijers J, Swaen G, Slangen J. 1997. Mortality of Dutch coal miners in relation to pneumoconiosis, chronic obstructive pulmonary disease, and lung function. Occup Environ Med 54(10):708-713.

16. Mine Safety and Health Administration, 2014. Lowering Miners' Exposure to Respirable Coal Mine Dust, Including Continuous Personal Dust Monitors. Federal Register 79(84).

17. Morfeld P, Lampert K, Ziegler H, Stegmaier C, Dhlom G, Piekarski C. 1997. Overall mortality and cancer mortality of coal miners: attempts to adjust for health worker selection effects. Ann Occup Hyg 41:346-51.

18. Nava S, Gregoretti C, Fanfulla F, Squadrone E, Grassi M, Carlucci A, Beltrame F, Navalesi P. 2005. Noninvasive ventilation to prevent respiratory failure after extubation in high-risk patients. Crit Care Med 33(11):2465-2470.

19. Ornek T, Atalay F, Erboy F, Altinsoy B, Tanriverdi H, Uygur F, Tor M. 2013. Is pneumoconiosis a factor of severity in acute exacerbation of chronic obstructive pulmonary disease? Clin Ter 164(6):473-7.

20. Patrick A, Blandford A, Waddell A, James R. 2014. Kentucky Coal Facts. Frankfort: Kentucky Energy and Environment Cabinet.

21. Petsonk E, Rose C, Cohen R. 2013. Coal mine dust lung disease. New Lessons from old exposure. Am J Respir Crit Care Med, 187(11):1178-85.

22. Rosenman K, Reilly M, Henneberger P. 2003. Estimating the total number of newly recognized silicosis cases in the United States. Am J Ind Med 44:141-147.

23. Santo Tomas L. 2011. Emphysema and chronic obstructive pulmonary disease in coal miners. Curr Opin Pulm Med 17(2):123-125.

24. Wang M, Beeckman-Wagner L, Wolfe A, Syamlal G, Petsonk E. 2013. Lung-function impairment among US underground coal miners, 2005-2009: geographic patterns and association with coal worker's pneumoconiosis. J Occup Environ Med, 55(7):846-50. 
25. World Health Organization (WHO). 2010. International Classification of Diseases, Tenth Revision. 


\section{Biographical Sketch}

Jake Beggs is originally from Paducah, KY. He received his Bachelor of Science degree in Kinesiology and Health Promotion from the University of Kentucky in 2013. He is currently a Master of Public Health (MPH) candidate in Environmental Health at the University of Kentucky and a NIOSH/CDC funded trainee through the Central Appalachian Regional Education and Research Center. Upon completion of the MPH, he will begin the Master of Science in Physician Assistant Studies (MSPAS) degree program from the University of Kentucky.

E-mail: jbe223@g.uky.edu

Phone: (270) $559-6334$ 


\section{Acknowledgments}

This work was supported by grant/cooperative agreement number 2460OH008483-10 from NIOSH. Its contents are solely the responsibility of the authors and do not necessarily represent the official views of NIOSH. NIOSH had no role in the study design; in the collection, analysis and interpretation of data; in the writing of the report; or in the decision to submit the article for publication.

I would like to thank the Kentucky Injury Prevention and Research Center, especially Dr. Terry Bunn and Dr. Svetla Slavova, for making this a challenging and rewarding project. I would also like to thank Dr. David Mannino for his continued support and guidance not only on this project, but throughout my time in the MPH program. I would like to thank the Central Appalachian Regional Education and Research Center for their support and providing many interesting educational and professional development opportunities. Finally, I would like to thank my peers and my family. 
Table 1. Age-Adjusted Mortality Rates from Pneumoconiosis and CWP in Kentucky, West Virginia, Pennsylvania, and US, 2003-2011, Ages 15 and over.

\begin{tabular}{|c|c|c|c|c|c|c|c|c|c|}
\hline & 2003 & 2004 & 2005 & 2006 & 2007 & 2008 & 2009 & 2010 & 2011 \\
\hline \multicolumn{10}{|l|}{ Kentucky } \\
\hline Pneumoconiosis ${ }^{\mathrm{a}}$ & 36.3 & 35 & 34.6 & 33.2 & 29.7 & 26.3 & 26.2 & 27.8 & 31.9 \\
\hline $\mathrm{CWP}^{\mathrm{a}}$ & 26.9 & 23.3 & 24.2 & 23.8 & 19.7 & 19.7 & 19.3 & 21.2 & 22.4 \\
\hline \multicolumn{10}{|l|}{ West Virginia } \\
\hline Pneumoconiosis $^{\mathrm{a}}$ & 132 & 123.5 & 117.7 & 120.5 & 99.7 & 104.1 & 96.8 & 90.8 & 80.6 \\
\hline $\mathrm{CWP}^{\mathrm{a}}$ & 84.4 & 79.8 & 62.7 & 81.3 & 63.9 & 59.7 & 55 & 50 & 41 \\
\hline \multicolumn{10}{|l|}{ Pennsylvania } \\
\hline Pneumoconiosis $^{\mathrm{a}}$ & 37.2 & 34.1 & 25.8 & 25.4 & 20.3 & 20.7 & 16.4 & 14.3 & 13.9 \\
\hline $\mathrm{CWP}^{\mathrm{a}}$ & 23.4 & 20.2 & 15.2 & 15.3 & 10.8 & 8.9 & 8.4 & 7.3 & 6.1 \\
\hline \multicolumn{10}{|l|}{ United States } \\
\hline Pneumoconiosis ${ }^{\mathrm{a}}$ & 11.6 & 11 & 10.4 & 9.7 & 9.1 & 8.8 & 8 & 8 & 7.2 \\
\hline $\mathrm{CWP}^{\mathrm{a}}$ & 3.4 & 3.1 & 2.8 & 2.8 & 2.2 & 1.9 & 1.9 & 1.9 & 1.6 \\
\hline
\end{tabular}


Table 2. Demographic Characteristics and Number of Deaths from Pneumoconiosis in Kentucky residents, 2011-2013, Ages 15 and over.

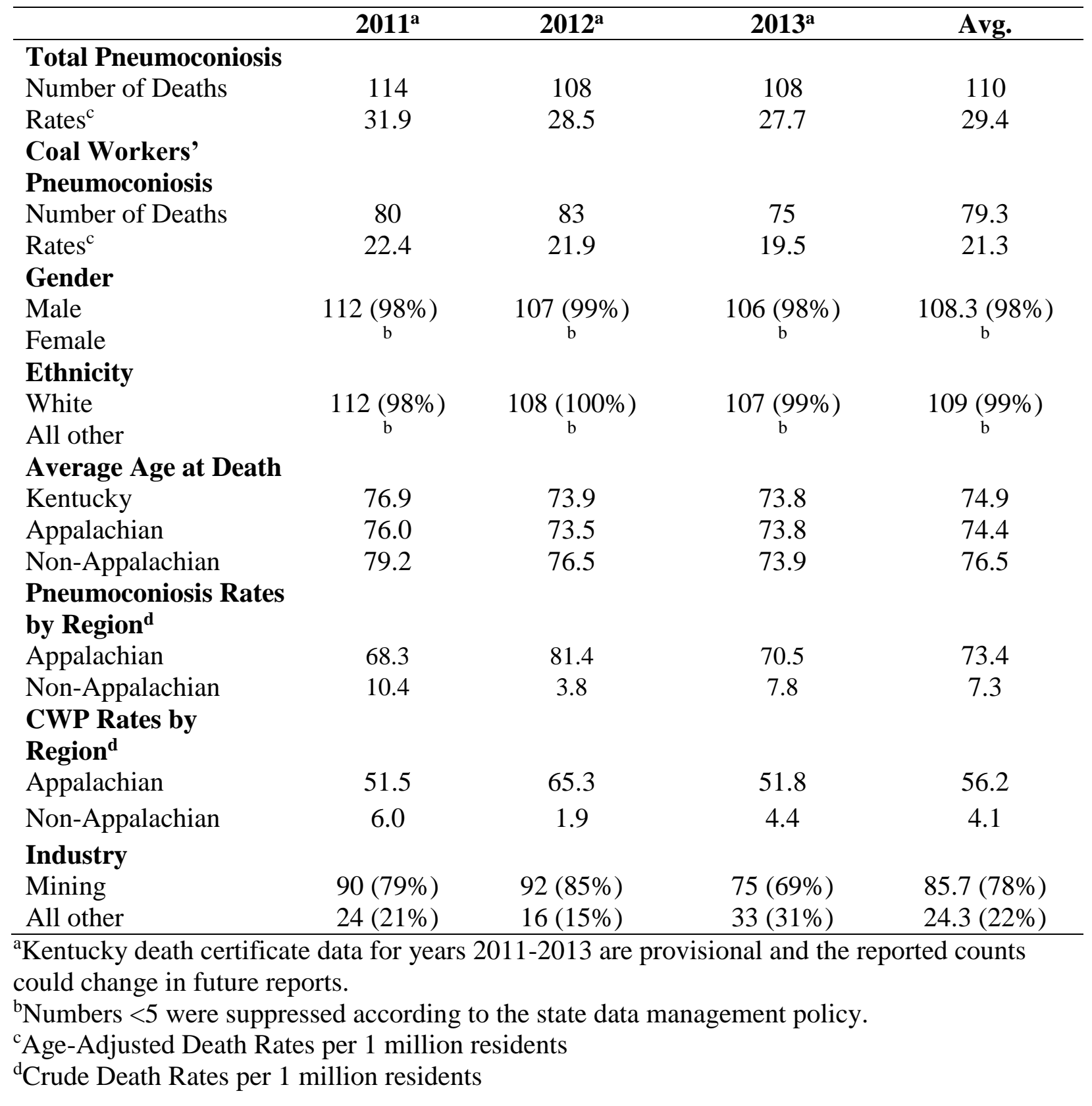


Table 3. Location of Pneumoconiosis Deaths in Kentucky, 2011-2013.

\begin{tabular}{lcccc}
\hline & $\mathbf{2 0 1 1}^{\mathbf{a}}$ & $\mathbf{2 0 1 2}^{\mathbf{a}}$ & $\mathbf{2 0 1 3}^{\mathbf{a}}$ & Avg \\
\hline Location & & & & \\
In-Patient & $62(54 \%)$ & $53(49 \%)$ & $42(39 \%)$ & $52.3(47 \%)$ \\
Residence & $37(33 \%)$ & $42(39 \%)$ & $41(38 \%)$ & $40.0(36 \%)$ \\
Nursing Home/ & $\mathrm{b}$ & $\mathrm{b}$ & $9(8 \%)$ & $5.7(5 \%)$ \\
Long-term Care & & $\mathrm{b}$ & $6(6 \%)$ & $\mathrm{b}$ \\
ER/Outpatient & $5(4 \%)$ & $5(5 \%)$ & $\mathrm{b}$ & $\mathrm{b}$ \\
Hospice & $\mathrm{b}$ & $\mathrm{b}$ & $7(7 \%)$ & $\mathrm{b}$ \\
Other & $\mathrm{b}$ & $\mathrm{b}$ & $\mathrm{b}$ &
\end{tabular}

${ }^{a}$ Kentucky death certificate data for years 2011-2013 are provisional and the reported counts could change in future reports.

${ }^{\mathrm{b}}$ Numbers $<5$ were suppressed according to the state data management policy. 
Figure 1. Total Pneumoconiosis Mortality Rates in WV, PA, and US, 2003-2011, and in KY, 2003-2013.

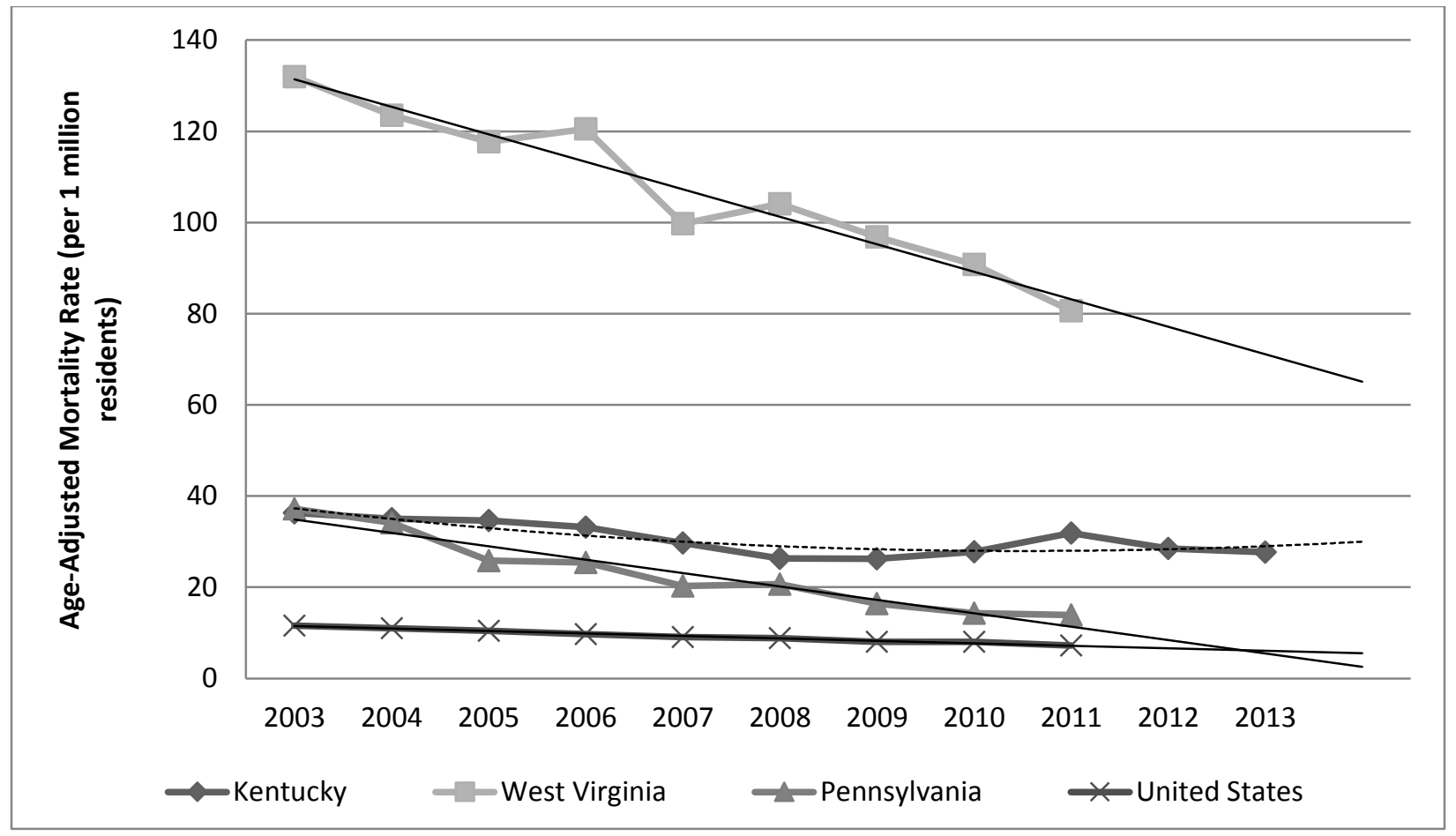


Figure2. Coal Worker's Pneumoconiosis Mortality Rates in KY, 2003-2013, and in WV, PA, and US, 2003-2011.

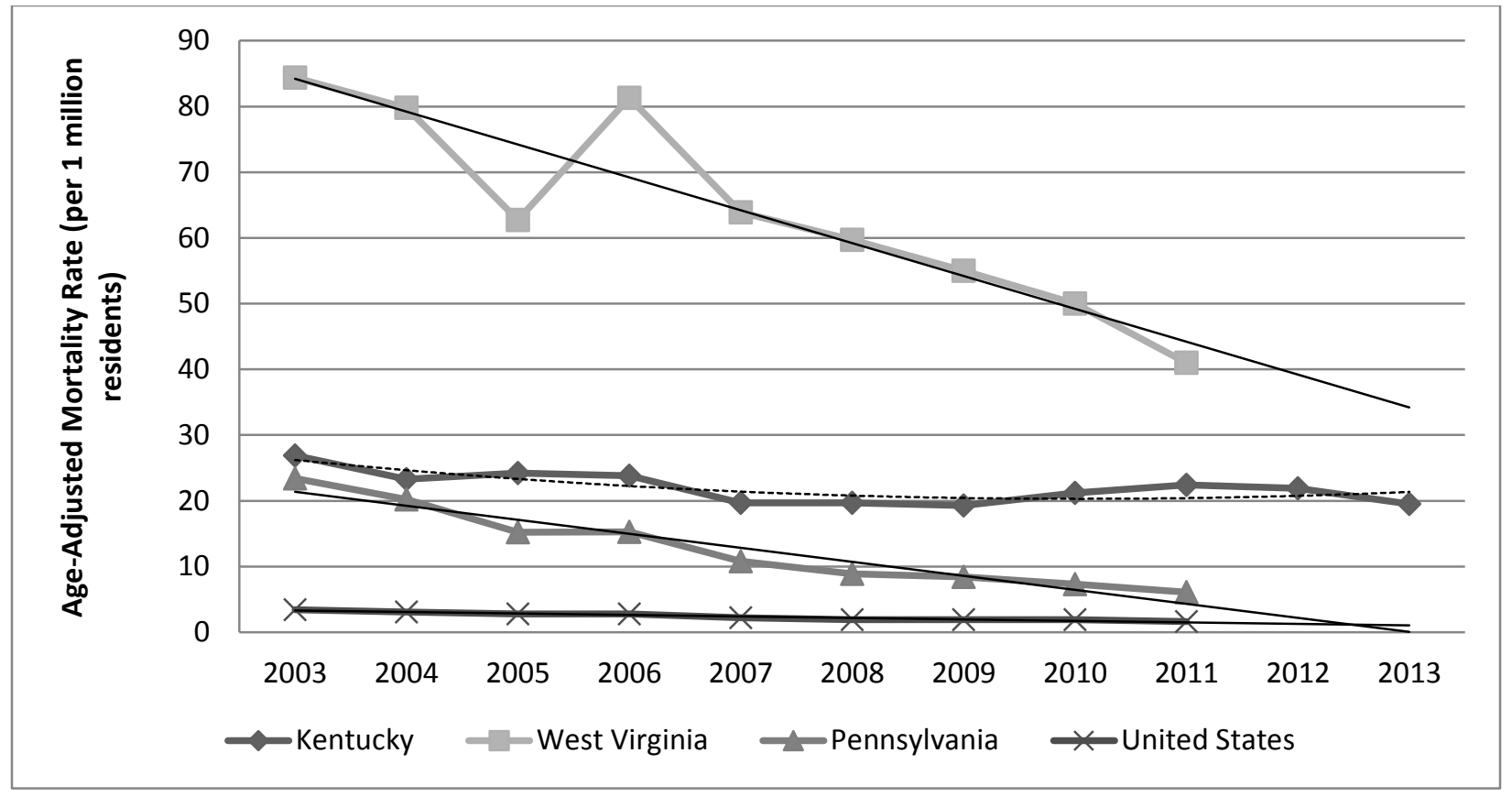


Figure 3. Immediate Cause of Death when Pneumoconiosis was the Underlying or Contributing Disease in Kentucky, 2011-2013.

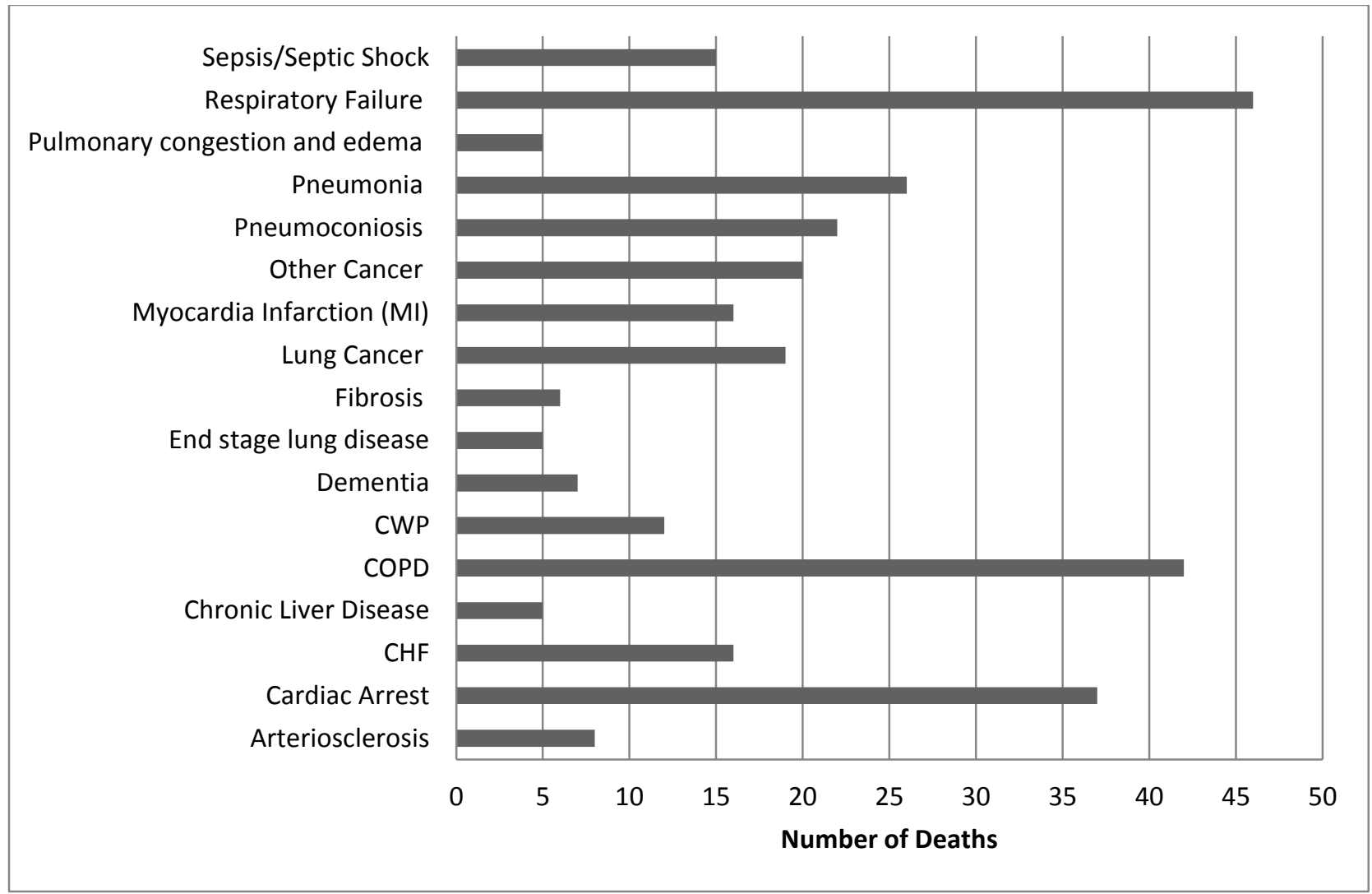


Figure 4. Autopsies performed and Certifier of Pneumoconiosis Deaths in Kentucky, 20112013.

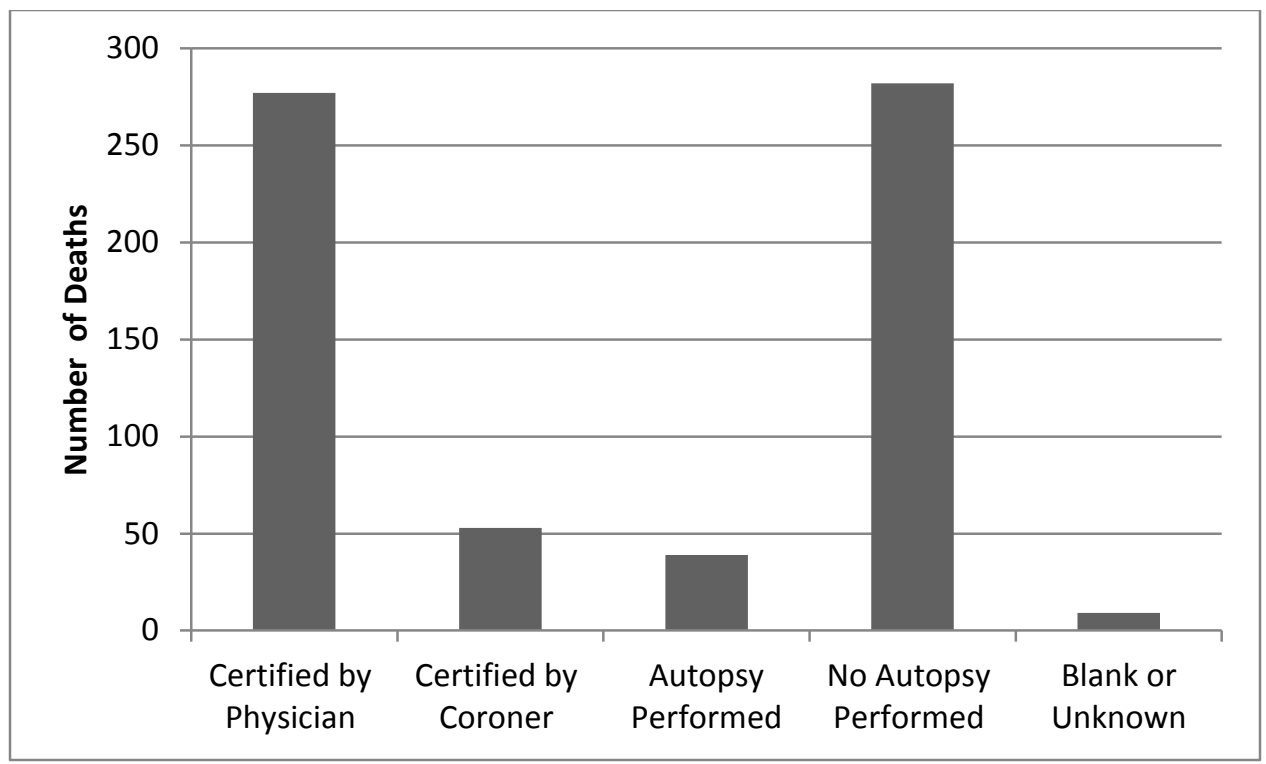

